\title{
An explanation of the profitability and market power of marginalized microenterprises
}

\section{Natanael Ramírez}

Professor and researcher at the School of Economics and International Relations of the Autonomous University of Bsaja California and member of the National Sistem of Researchers

$$
\begin{aligned}
& \text { natanael@uabc.edu.mx } \\
& \text { Alejandro Mungaray }
\end{aligned}
$$

Professor and researcher at the School of Economics and International Relations of the Autonomous University of Baja California and member of the National Sistem of Researchers

$$
\begin{gathered}
\text { mungaray@uabc.edu.mx } \\
\text { José G. Aguilar }
\end{gathered}
$$

Professor and researcher at the School of Economics and International Relations of the Autonomous University of Bsaja California and member of the National Sistem of Researchers

$$
\begin{aligned}
& \text { gaba@uabc.edu.mx } \\
& \text { Ramón Inzunza }
\end{aligned}
$$

Professor and researcher at the University of South Sierra of Oaxaca, Mexico and member of the National

$$
\text { Sistem of Researchers }
$$

riaxyzmx@hotmail.com

\begin{abstract}
This paper analyzes the behavior of marginalized microenterprises under an imperfect competition framework, where said economic units are capable of fixing a price above their marginal costs which allows them to survive and even be profitable despite their typical operating conditions. To prove this, we use an econometric model that considers the Lerner index as a variable dependent on a set of qualitative variables previously classified in accordance to their area of influence. We conclude that these microenterprises are capable of being profitable and operate with market power through their advertising and sales strategies and the flexibility in their productive process. In any case the pricing power is highly influenced by the socioeconomic conditions of the market in which it operates.
\end{abstract}

Key words: Microenterprises, market power, marginalization, Lerner's Index.

JEL: D4, D41, D21

\section{Academic Discipline and Sub - Disciplines}

Economic: Industrial Organization

\section{Council for Innovative Research}

\author{
Peer Review Research Publishing System
}

Journal: Journal of Social Sciences Research

Vol. 10, No. 1

www.cirworld.com, editor@cirworld.com 


\section{Introduction}

In recent years, the analysis of microenterprises has emerged as an important research topic due to its participation in the business sector and its significant contribution to employment. Several papers have demonstrated the power this sector has to absorb at times of crisis the jobs that medium and large companies are unable to retain (Georgellis, Sessions \&Tsitsianis, 2005). Furthermore, it has also been demonstrated that microenterprises have a larger capacity to adjust to market movements, therefore responding to a fluctuating demand in a more efficient manner (Mills \& Schumann, 1985; Audretsch\&Yamawaki, 1991).

Despite the social and economic importance of these limited economic units in developing countries, analysis of their competitive behavior, the competition framework on which they operate, and the mechanisms implemented for their survival, is scarce (Palacio, 2002). It has been traditionally assumed that they are ruled within a perfect competition framework due to the fact that they are many in number and have a small production scale. However, several studies have demonstrated that the size of the company is not a conditioning factor on the market power with which it operates as product differentiation and geographic location, amongst other factors, can allow even the smallest enterprise to have certain degree of market power (Shama, 1993; Barla, 2000; and Vázquez, 2005). In this respect, empirical research has shown that microenterprises that emerge in the fringes of large cities can operate with market power due to the differentiation achieved by its geographic location in marginalized areas. This differentiation helps them to capture a demand that is of little interest to medium and large companies because of the higher transaction costs involved in reaching small neighborhood niches (Mungarayet al., 2005).

The objective of this paper is to determine factors that allow marginalized microenterprises to fix prices above marginal operating costs despite the technical conditions within which they operate thus acting with market power. This work supports the hypothesis that microenterprises that are able to operate with market power are those that differentiate themselves through actions related to offering a better product and improving customer service but also exploiting the qualities of the point of sale and geographic conditions. The paper is organized in the following manner: In the second part, there is a review of the literature regarding market power of microenterprises.Afterwards, we describe information sources and propose an empirical model that allows us to measure which variables have a larger effect on the transference of market power to microenterprises on the next section results are discussed under the framework of current debate; and finally we present the main conclusions and limitations of the research.

\section{Market power in microenterprise}

Market power is the ability of a firm to profitably raise the market price of the good or service over marginal cost (Parkin\& Esquivel, 2001). According to Stoft (2002) market power implies the capacity of company to alter the price on its own benefit in relation with competitive levels. According to the classic Structure-Conduct-Performance(SCP) paradigm (Sylos, 1966), when as product of an intense competition there are few companies in the market and these have a significant participation in total sales, this facilitates the emergence of monopolistic behaviors that influence fixing a price above the competition thus causing a decline in the social well-being (Fariñas\&y Huergo, 2003). This is associated with the market power of the enterprise resulting of a competition that eliminates and absorbs others and facilitates the entrance of new ones (Clarke, 2000).

This definition considers that it is only the larger companies that concentrate the greatest portion of market sales and can successfully exert practices associated with market power. When researching whether this capability is also related to other variables such as the degree of product differentiation, geographic location of the enterprise and customer loyalty in his theory of localization, Hotelling (1929) proposes that geographic location could concede market power to a companydue to the presence of homogeneous or substitute goods nearby, therefore, consumers whose location is near a company, will have to incur in a "high" transaction cost to consume at a competing enterprise. This can be capitalized upon by the closer company by moderately increasing prices. This situation is highly frequent in the microenterprise sector of commercial units located in the outskirts of the city or marginalized areas, where through catering to neighborhood niches they survive and even reach profitability, (Mungarayet al., 2005). According to this approach, the higher the level of marginalization, the location will allow microenterprise enact more market power.

Recent studies show that microenterprises established in the most economically vulnerable areas are capable of building a degree of differentiation that allows them to fix prices above marginal operating costs (Davies et al., 1984; Daniels, 1999; Mungarayet al., 2007). Orlando \& Pollack (2000) find that, in Latin American, microenterprises established in poor areas survive, even several years, protected by the marginalized situation of the context becoming even more stable than those established in neighborhoods that are more affluent with higher spending power.

Despite the fact that there are important advances in the identification and measurement of the capacity of microenterprises to operate with market power, according toBresnahan (1989), literature does not present compelling arguments about its nature and relation with other factors such as technology implemented, product quality, consumer loyalty or the micro-entrepreneur's training. In fact, there is still much to research in regards to whether social and economic marginalization are a necessary or sufficient condition for the emergence of market power in a microenterprise with operational limitations. For example, it is natural in every industry that some companies are more efficient than others whether it is because they have better technology, more years in the market and a better direction (Demsetz, 1974). It is common for large enterprises to try to better their competitive positions through technological innovation and product differentiation. 
The theory of human capital states that some inherent attributes of people such as education and health, can be considered as factors that bring economic benefits to individuals as organizations (Schultz, 1960 \& 1971). In this sense, an increase in the level of training as a strategy to strengthen the cognitive abilities of the owner and the workers thus boosting the productivity levels of the workers while strengthening entrepreneurial abilities which is a conditioning factor of market power (Mungarayet al., 2007). On the other hand, in regards to microenterprises the absence of health of the promoter is usually the beginning of the end of the business venture.

Borch\&Forsman (1999) consider three strategies of marketplace positioning: client differentiation through segmentation based on criteria such as age, education level, income level, social, amongst others; product differentiation,which considers diverse ranges in quality, fashions and tastes; and the differentiation by advertising, which through marketing strategies allows mid-term adjustment of customer preferences. While these strategies facilitate the manipulation of pricing levels in the smallest companies, these opportunities are quite limited.

The positioning of the product on distribution channels, allows us to extend market dimensions and reduce costs in medium and large enterprise trough subcontracting. This commercial alternative provides certainty in regards to sales levels and allows planning in regards to profit, costs, inventory and investment (Mungaray\&Ramírez, 2004). This along with product distribution and the location on which the microenterprise is established can be considered an important variable specially at the start of operations as a bad decision in this respect might represent a strong barrier for the evolution of the enterprise (Audretsch, 2001) and it is very likely that at the beginning the enterprise does not possess the capital to correct such error.

\section{Methodology}

Authors such as Davies et al. (1984), Daniels (1999), and Mungarayet al. (2007), agree on variables that can both in an individual and combined manner favor that a few enterprises control a market when their levels are adequate to excel in a specific competitive environment. Some of these variables are: the degree of product adaptation and empathy to client necessities, the type of technology employed, advertising budget, distribution channels and points of sale created, enterprise longevity, owner and employee training levels, employee productivity, infrastructure, and services where the enterprise is located.

Four groups can be identified amongst these variables: product qualities, employee qualities, establishment qualities and market qualities. In the realm of product qualities, some strategies refer to elevating product quality and adapting and diversifying selection to better satisfy client demand. Within work force qualities training level of owners and personnel, number of workers and their productivity may be considered as determining factors. Regarding establishment qualities we may analyze factors such as the type of advertising used, management of distribution channels and outlets, outsourcing options and longevity of the company. Amongst market qualities, when faced with a lack of information regarding the direct opinion of consumers the marginalization index may work as a proxy variable of the socioeconomic conditions of the microenterprise's clients.

\subsection{Econometric Model}

The model is derived from the one implemented byMungarayet al. (2007), which assumes that each microenterprise is operating in an imperfect competition environment and that the emergence of market power is possible. This model considers the Lerner index (1934) as a relative measurement and the dependent variable which is estimated through the following equation:

$$
L_{i}=\left(\frac{P_{i}-C m g_{i}}{P_{i}}\right)
$$

where for the companyi, the Lerner index is denoted by $L_{i}$, the price of its product is represented by $P_{i}$, and its marginal cost by $\mathrm{Cmg}_{i}$. Huergo (2001) mentions that when marginal costs can't be computed, a good approximation may be the average good production cost, therefore the Lerner index may be restated as:

$$
L_{i}=\left(\frac{P_{i}-C m e_{i}}{P_{i}}\right)
$$

This index has the potential to measure the company's capacity to sustain positive demand despite price increases. The model therefore measures its relation to groups of qualitative variables associated with establishment, workforce, product and market qualities under the following specification:

$$
L=\beta_{0}+\boldsymbol{\beta}_{a} \mathbf{X}+\boldsymbol{\beta}_{b} \mathbf{Y}+\boldsymbol{\beta}_{c} \mathbf{Z}+\boldsymbol{\beta}_{d} \mathbf{V}+\mu
$$

where Lshows the Lerner index; $\mathbf{X}$ is the vector representing establishment qualities, Yis the vector representing workforce qualities,Zis the vector representing product qualitiesandVmarket qualities. The parameters $\boldsymbol{\beta}_{a}, \boldsymbol{\beta}_{b}, \boldsymbol{\beta}_{c}$ and $\boldsymbol{\beta}_{d}$ represent the respective coefficientsof each of the determinants in the same sequence.

\subsection{Building the marginalization index}

According to the Mexican Population Council (CONAPO, for its acronym in Spanish), marginalization is a structural phenomenon originated by historical development patterns. This is expressed through the difficulty to propagate technical progress within local productive contexts and the exclusion of certain social segments from the benefits of development. For the construction of a marginalization index, this paper takes into account the spatial intensity of nine manifestations of 
exclusion measured by the percentages of population for whom the enjoyment of certain goods and services that are essential to development is not possible.

These indicators of economic marginalization associated to housing exclusion are: the percentage of occupants in private homes without running water; the percentage of occupants in houses without drainage system; the percentage of occupants in houses without electricity; the percentage of occupants in houses with dirt floors; the percentage of households with high levels of overcrowding; the percentage of employed population with incomes up to twice the minimum wage; the percentage of the population 15 years and over who are illiterate; the percentage of population aged 15 or older who has not completed primary school; and the percentage of population living in towns of less than 5,000 inhabitants.

To estimate the marginalization index, we considered the 2010 Mexican Population and Housing Census as the main information source, largely because it has the degree of coverage and detail necessary to build on both a state and municipal level. The marginalization index by geographical area was constructed based on the methodology implemented by CONAPO in its state and municipal marginalization index for Mexico in 2000, for which the principal components technique is consideredby the following equation:

$$
I M_{j}=\sum_{i=1}^{w} F P_{i} \frac{\left(X_{i, j}-\bar{X}_{i}\right)}{d_{i}}
$$

where $I M_{j}$ is the marginalization index of the geographic unit $j$. Furthermore, the indicator $i, X_{i, j}$ is the value taken in the geographical unit $j, \bar{X}_{i}$ is its mean, $d_{i}$ is its standard deviation, $d_{i}$ is its standard deviation and $F P_{i}$ is its ponderation factor. The total of marginalization indicators is $w$.

Considering that the Lerner and marginalization index described in equations 2 and 4 respectively, and that the qualitative variables grouped in equation 3 , the model to be estimated is represented on a disaggregated basis by the following equation:

$$
\begin{aligned}
L_{i}=\beta_{0} & +\beta_{1} A O_{i}+\beta_{2} P B_{i}+\beta_{3} L V_{i}+\beta_{4} E V_{i}+\beta_{5} A D_{i}+\beta_{6} N T_{i}+\beta_{7} I P_{i}+\beta_{8} M P_{i}+\beta_{9} D P_{i}+\beta_{10} A P_{i}+\beta_{11} I M_{i} \\
& +\mu_{i}
\end{aligned}
$$

where, particularizing for the microenterprise $i$,the variable $A O_{i}$ represents the years of operation; $P B_{i}$ is the level of advertising that consists of a dummy that takes on the value of 1 if the microenterprise is applying a publicity strategy and 0 otherwise. The point of sale is represented by the expression $L V_{i}$, which takes the value of 1 if the microenterprise is itinerant, 2 when the establishment is located in the public way regularly, 3 if the microenterprise uses a particular houseas a point of sale, 4 if they are located in an established space independent of the home. The term $E V_{i}$ refers to the existence of sale strategies, in which case it will take the value of 1 when one is applied and 0 when there is not. $A D_{i}$ refers to the renovation of the establishment layout that implies adjustments in the productive process and will take on the value of 1 when they have taken place within the last year and 0 otherwise. $N T_{i}$ represents the number of workers. $I P_{i}$ is a proxy variable for productivity that is calculated dividing the value of monthly production between the number of workers; the variables $M P_{i}, D P_{i}$ and $A P_{i}$ capture the effects of changes to the product to better it, differentiate it or adapt it respectively with dummy variables that take the value of 1 when changes have occurred and 0 in any other case. The marginalization index of the neighborhood where the microenterprise $i$ is located is given by $I M_{i}$; lastly, $\mu_{i}$ represents model errors and the parameters $\beta_{1}, \ldots, \beta_{11}$ are coeficients that measure the relationship level between the Lerner index and the described explanatory variables.

\subsection{Information sources}

The information was obtained from the Program for Research, Assistance and Teaching for the Micro and Small Enterprise (PIADMyPE) at Universidad Autónoma de Baja California, which provides technical assistance in administrative, production, costs and fiscal matters to marginalized microenterprises in the state of Baja California, Mexico. Through instruments such as the diagnostic survey and operational log, it is possible to obtain information necessary to follow up with participating companies.

We selected a random sample of 1,323 microenterprises registered in the program that operate in the neighborhoods with the highest poverty and marginalization levels within the state, where also the level of training of the micro-entrepreneur (see table 1). Microenterprises considered in our sample operated within the commercial, manufacture and services sectors in the major towns in the state of Baja California.

In this marginalization context, $66 \%$ of the analyzed microenterprises were led by a woman, which is a consequence that the emergence and operation of the majority of microenterprises is closely linked to the family climate. In developing countries, the decision to start a small business is often a result of the need to increase the bargaining power in the home by the woman (Pollack, 2005), making it common for housewives to decide to embark on one of these business ventures. 
Table 1. Sample description

\begin{tabular}{lccccccccc}
\hline \hline \multicolumn{1}{c}{ Sector } & $\begin{array}{c}\text { Ensenada } \\
(\mathbf{1 3 \% )}\end{array}$ & $\%$ & $\begin{array}{c}\text { Mexicali } \\
\mathbf{- 4 3 \%}\end{array}$ & $\%$ & $\begin{array}{c}\text { Tecate } \\
\mathbf{( 3 \% )}\end{array}$ & $\%$ & $\begin{array}{c}\text { Tijuana } \\
\mathbf{( 4 0 \% )}\end{array}$ & $\%$ & $\begin{array}{c}\text { Total } \\
\mathbf{( 1 0 0 \% )}\end{array}$ \\
Commerce & 64 & $38 \%$ & 218 & $38 \%$ & 19 & $41 \%$ & 277 & $52 \%$ & $\mathbf{5 7 8}$ \\
Services & 55 & $32 \%$ & 210 & $37 \%$ & 23 & $50 \%$ & 157 & $29 \%$ & $\mathbf{4 4 5}$ \\
Manufacture & 51 & $30 \%$ & 144 & $25 \%$ & 4 & $9 \%$ & 101 & $19 \%$ & $\mathbf{3 0 0}$ \\
Total & $\mathbf{1 7 0}$ & $100 \%$ & $\mathbf{5 7 2}$ & $100 \%$ & $\mathbf{4 6}$ & $100 \%$ & $\mathbf{5 3 5}$ & $100 \%$ & $\mathbf{1 3 2 3}$ \\
\hline \hline
\end{tabular}

Source: Based on data from PIADMYPE

\section{Results analysis}

The results of estimating equation 5 are presented in Table 2 and show that only four of 11 explanatory variables included in the model were statistically significant at $90 \%$ confidence level or higher, therefore only partially confirming the hypothesis. Three of the variables capable of explaining market power in microenterprises located in marginalized areas stand out in the qualities of the property, such as advertising, sales strategy and implementing local adjustments made to suit the customer needs. This allows to state that customer proximity and loyalty developed allow the micro-entrepreneur some power to increase the price. However, the results indicate that for this type of business, location and antiquity of the business for themselves do not confer market power.

For Parking and Esquivel (2006), the boost from advertising is important in order to adequately convey the quality of the products offered, compromise with the consumer to a minimal quality or persuade him through presentation. Regardless, considering the precarious conditions of any of these microenterprises and the scarce connections with possible suppliers for innovative presentations for their product, it is quite few that consider investing in this area. Despite its importance, this activity is undervalued and under exploited by micro-entrepreneurs due to the lack of funds to pay for a strategic marketing plan or lack of training to do it themselves, including the limited use of information technologies that are increasingly used such as social networks to market and distribute their products. This represents a great opportunity to improve their competitive position through the differentiation of their artisanal qualities over those that are the result of industrialized labor whether it be either in the health (in the case of food) or artistic fields (in the case of ornamental objects).

Having a sales strategy aimed at better service, has a positive relationship with the dependent variable. However, despite its importance, only $40 \%$ of micro enterprises considered in the sample report using some kind of strategy to improve sales. Vázquez (2005) suggests that relationships with entrepreneurs through partnerships, such as with customers through market research, favor the emergence of innovations that create competitive advantage, making the customer strategy cornerstone to the success of micro business. Within the conventional service strategies are close treatment, timely service and home delivery.

The adaptation of processes or the establishment to tailor to customers changing needs matches the classic results of Borch\&Forsman (1999), in the sense that a continuous adaptation of the microenterprises in order to achieve customer segmentation, allows the consumer to feel taken into consideration and allows him to trust that the company will adjust to respond to customer recommendations. This might grant an advantage over chain supermarkets and self-service which are less flexible due to their market heterogeneity, or slower due to their decision-making structure.

The average age of the sampled companies, which is two years bears no relation with the dependent variable, as these microenterprises associate themselves with economic survival as there is no clearly defined barrier between the business and family management, inhibiting its growth. In the specific case of location, the results indicate that micro-enterprises in areas of high deprivation, dependability, independence and stability of the shop, do not give it greater ability to market the microenterprise. Although an independent and stable space allow the customer to feel identified with the company - in the absence of branding-, the micro-entrepreneur of informal nature uses other instruments valued by potential customers to build trust even if your project is itinerant.

Table 2. Econometric Results

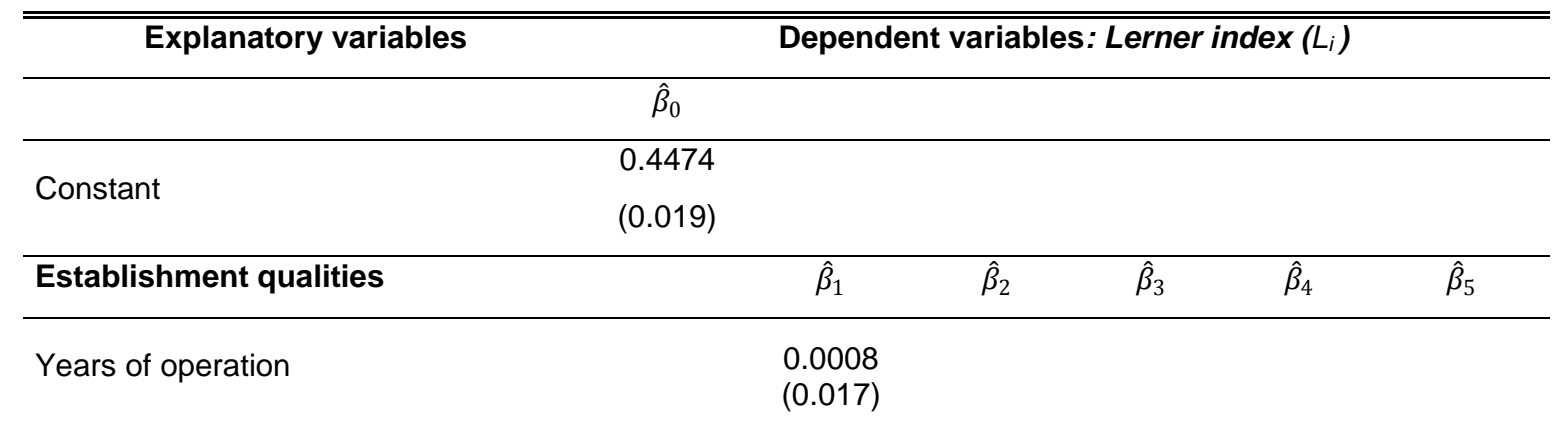


$\begin{array}{ll}\text { Advertising } & 0.0309^{*} \\ & (0.013)\end{array}$

Point of sale

0.0034

$(0.005)$

Sales strategy

$0.0130^{* \star}$

$(0.007)$

Production processes or space adaptations

$0.0395^{*}$

(0.014)

\begin{tabular}{lcc}
\hline Workforce qualities & $\hat{\beta}_{6}$ & $\hat{\beta}_{7}$ \\
\hline Number of workers & -0.0033 & \\
& $(0.004)$ &
\end{tabular}

Productivity

0.0002

\begin{tabular}{lccc} 
& \multicolumn{3}{c}{$(0.0001)$} \\
\hline \multicolumn{1}{c}{ Product qualities } & $\hat{\beta}_{8}$ & $\hat{\beta}_{9}$ & $\hat{\beta}_{10}$ \\
\hline Product improvements & -0.0054 & \\
& $(0.001)$ & \\
Product diversification & & -0.0181 & \\
& & $(0.014)$ & \\
Product adaptation & & -0.0085 \\
\multicolumn{1}{c}{ Market environment } & & $(0.018)$ \\
\hline \multirow{2}{*}{ Marginalization index } & $\hat{\beta}_{11}$ & \\
& $0.0018^{* \star}$ & \\
\hline $\mathrm{R}^{2}=0.22$. Durbin-WatsonTest :1.82. & $(0.001)$ & \\
F-statistical:2.45, Prob (0.0049). & Ramsey Test: 1.4, Prob(0.23). \\
\hline
\end{tabular}

*Significant at95\%. ${ }^{* *}$ Significant at90\%. Parenthesis indicate standard errors.

Regarding the qualities of workers, neither the number of employees nor productivity by themselves wereassociated with market power. It is likely that this is related to the fact that $80 \%$ of workers in these enterprises are familiar and in many cases involve helpers with no fixed payment, so that inefficiencies in productivity are absorbed by the same employees, preventing the possibility of imposing price by the micro-entrepreneur.

The specific product qualities considered also did not show a clear influence on the ability of market power arising in small businesses developing in marginalized environments. In the case of product diversification, the lack of a relation could be associated to the fact that these businesses are of an artisanal nature, making it complex for a consumer to differentiate a diversification strategy from personalized attention by the staff (Borch\&Forsman, 2004).

Finally, the market environment as measured by the marginality index shows a positive relationship with the Lerner index. This supports findings presented in previous works like Mungarayet al. (2007) where it is argued that areas of marginalization in which micro-enterprises are located, with significant levels of insecurity, infrastructure and /or communication deficiencies, offer natural protection against the entry of new competitors, giving the former the ability to set prices. In any case, it is a short-term benefit because the entry barriers for capital and technology are low, so it will depend on the microenterprise transform this opportunity into a real competitive advantage through increased efficiency of its processes and improve the quality and degree of differentiation achieved with their products.

\section{Conclusions}

Mexican business structure is composed mostly of microenterprises, which are the main source of employment and contributing $42 \%$ of the total employed population. In recent years these economic units have become a natural tool to offset the tightening of the labor market and unemployment that medium and large companies are generating in a time of crisis when the face falling demand for its products. Although the vast majority of these enterprises emerge by necessity, entrepreneurs can set prices for its products above market levels even though their production processes are of low added value. 
This paper identifies that the endogenous factors that have greater involvement in the market power of microenterprises arising environments of marginalization, are the strategic aspects of the business and market environment, and those which are less associated with the qualities of its workers and the product they sell.

The challenge for these organizations is to overcome the survival trap derived from a basic demand that provides a shortterm income and inhibits a decapitalization by wear of capital goods. Promoting mechanisms for these enterprises to, despite their productive restrictions, improve their training and practices of customer service as a space to innovate and compete on price without sacrificing the quality of their products. This will allow us to create continuous improvement cycles that help increase profitability, attracting new markets and thereby achieving overcoming a survival operating mode.

Considering the market as a dynamic process, the variables associated with the overall management of the establishment are those that compensate for many of the difficulties and inefficiencies of these enterprises and improve the level of income. When designing policies to promote microenterprise development, we should promote competing schemes based on the quality, innovation and production efficiency while eliminating barriers to competition that favor trade based on overpriced products, so that the welfare microenterprises can also give reflected in the community they serve, while stimulating those looking for ways to increase their income and grow, as it could be through their specialization and integration into production chains with medium and large companies.

\section{Bibliography}

[1] Audretsch, David, (2001), "Research issues relating to structure, competition, and performance of small technologybased firms", Small Business Economics, Vol. 16, pp. 37-51.

[2] Audretsch, David andYamawaki, Hideki, (Editores), (1991), Structure, conduct and performance, New York University Press. $437 \mathrm{p}$.

[3] Barla, Philippe, (2000), "Firm size inequality and market power", International Journal of Industrial Organization, Vol 18, pp.693-722.

[4] Borch, Odd-Jarl Forsman, Sari, (1999), "The competitive tools and capabilities of micro firms in the Nordic food sectora comparative study". In S.O. Borgen (Ed.). The food sector in transition - Nordic Research.Proceedings of NJFseminar No. 313, June 2000. NILF-Report 2001-2. Oslo: Norwegian Agricultural Economics Research Institute, pp. 3350.

[5] Borch, Odd-Jarl andForsman, Sari (2004), "Competitive positioning and resource configuration of small firms in a mature industry".In T. Cooney and P.Malinen (Ed.) New perspective on firm growth, $1^{\text {st }}$ Inter-Rent online publication, Europan council for small business and entrepreneurship, Turko, Finland.

[6] Bresnahan, Timothy, (1989), "Empirical studies of industries with market power", en R. Schmalenseeand R. Willig (editors), Handbook of Industrial Organization, Vol. 2 (cap. 17), pp. 1011-1057.

[7] Clarke, Roger, (2000), "Economía Industrial”, Ed. El colegio de economistas de Madrid and celestes, Madrid, España, $295 \mathrm{p}$.

[8] Daniels, Lisa, (1999), "The role of small enterprises in the household and national economy in Kenya: A significant contribution or a last resort?", World Development, Vol. 27(1), January, pp. 55-65.

[9] Davies, Stephen; Seale, James; Mead, Donald; Badr, Mahmoud; Sheikh, Nadia andSaidi, Abdel, (1984), "Small enterprises in Egypt: A study of two Governorates", MSU International Development Papers, Working Paper No. 16, East Lansing: Michigan State University, Department of Agricultural Economics. 100 p.

[10] Demsetz, Harold, (1974), "Two systems of belief about monopoly", in Harvey Goldschmid, et al., eds., Industrial Concentration: the New Learning. Boston: Little-Brown.

[11] Fariñas, José, andHuergo, Elena, (2003), "Profit margins, adjustment costs and the business cycle: An application to Spanish manufacturing firms", Oxford Bulletin of Economics and Statistics, vol. 65(1), febrero, pp. 49-72.

[12] Georgellis, Yannis; Sessions, John G. andTsitsianis, Nikolaos, (2005), "Self-employment longitudinal dynamics: A review of the literature", Economic Issues, Vol. 10, No. 2, pp. 51-84.

[13] Hotelling, Harold, (1929), "Stability in competition", The Economic Journal, Vol. 39, No. 153, pp. 41-57.

[14] Huergo, Elena, (2001), "El diagnóstico de poder de mercado en economía industrial: Una revisión de la literatura empírica española del siglo XX", Documento de Trabajo 0112 de la Universidad Complutense de Madrid.

[15] Lerner, Abba, (1934), "The concept of monopoly and the measurement of monopoly power", Review of Economic Studies, Vol. 1 No. 3, June, pp. 157-175.

[16] Mills, David and Schumann, Laurence, (1985),"Industry structure with fluctuating demand",American Economic Review,Vol. 75, No. 4, pp. 758-767.

[17] Mungaray, Alejandro and Ramírez, Natanael, (2004), "Subcontratación en microempresas y pequeñas empresas de Baja California”, Frontera Norte, Vol. 16, No. 32, pp. 35-62. 


\section{ISSN 2321-1091}

[18] Mungaray, Alejandro; Ramírez, NatanaelandTexis, Michelle, (2005), "Estructura de mercado y maximización de beneficios en las microempresas", Comercio Exterior, Vol. 55, No. 4, abril, pp. 316-321.

[19] Mungaray, Alejandro; Ramírez, Natanael; Aguilar, José G. and Beltrán, José M., (2007), "Poder de mercado en Microempresas de Baja California", Problemas del Desarrollo, vol. 38, No. 148, pp. 173-194.

[20] Orlando, M. Beatriz andy Pollack, Molly, (2000), Microenterprises and poverty: evidence from Latin America, Washington DC: Inter-American Development Bank.

[21] Palacio, Juan I., (2002), "Política industrial activa para microempresas en el funcionamiento de los mercados: Una perspectiva Española", en A. Mungaray, J. I. Palacio y C. Ruiz-Durán (coords.), Potencial de la vinculación universitaria para una política microempresarial: Una perspectiva comparada, México, M. A. Porrúa-UABC-UCLM, pp. 37-68.

[22] Parkin, Michael andy Esquivel, Gerardo, (2006), Microeconomía: Versión para Latinoamérica, México: Pearson Educación. 584 p.

[23] Pollack, Robert, (2005), "Bargaining power in marriage: Earnings, wage rates, and household production”, NBER Working Paper No. 11239, Washington University.

[24] Shama, Avraham, (1993), "Marketing strategies during recession: a comparison of small and large firm", Journal of Small Business Management, Julie, Vol. 31. No. 3. pp. 62-72.

[25] Shultz, Theodore, (1960), “Capital formation by education”, Journal of Political Economy, Vol. 68, pp. 571-583.

[26] Schultz, Theodore, (1971), "Investment in Human Capital".In Ronald Wykstra (ed.) Education and the economics of human capital.New York: The Free Press, pp. 23-41.

[27] Stoft, Steven, (2002), Power System Economics: Designing Markets for Electricity, New York: IEEE Wiley Press. 496 p.

[28] Sylos, Labini, (1966), Oligopolio y Progreso Técnico, Barcelona, Ediciones Oikos, 95 p.

[29] Vázquez-Barquero, Antonio, (2005), Las nuevas fuerzas del desarrollo, Editorial Antoni Bosch, Barcelona. 192 p.

1. 